\title{
Structure-dependent phytoplankton photosynthesis and production rates: implications for the formation, maintenance, and decline of plankton patches
}

\author{
Susanne Menden-Deuer* \\ Graduate School of Oceanography, University of Rhode Island, Rhode Island, USA
}

\begin{abstract}
Photosynthesis-irradiance relationships ( $P$ vs. $E$ ) were quantified for taxonomically diverse phytoplankton communities to determine whether differential net growth could be a mechanism leading to phytoplankton patchiness. The average $P$ vs. E parameters from 3 field seasons in summer 2007 and 2008 and spring 2009 in a shallow fjord (East Sound, Washington, USA) suggested a high light-adapted but light-limited phytoplankton community with maximum photosynthesis rate $\left(P_{\max }^{B}\right)$ of $3.80( \pm 0.19 \mathrm{SE}) \mathrm{mgC}\left(\mathrm{mg} \mathrm{chl} \mathrm{a}^{-1} \mathrm{~h}^{-1}\right.$; light utilization coefficient $(\alpha)$ of $0.013( \pm 0.0008) \mathrm{mgC}(\mathrm{mg} \mathrm{chl} \mathrm{a})^{-1} \mathrm{~h}^{-1}\left(\mu \mathrm{mol} \text { photons } \mathrm{m}^{-2} \mathrm{~s}^{-1}\right)^{-1}$, and light saturation index $\left(E_{k}\right)$ of $391( \pm 24) \mu \mathrm{mol}$ photons $\mathrm{m}^{-2} \mathrm{~s}^{-1} . P^{B}{ }_{\text {max }}$ and $\alpha$ for phytoplankton communities inside patches were $\geq 30 \%$ higher than for those outside patches. Primary production was higher inside patches due to both an intrinsically higher photosynthetic capacity and exposure to higher light intensities. Patches only occupied $\sim 12 \%$ of the water column but generated $>50 \%$ of total water column production (1117 $\mathrm{mg} \mathrm{C} \mathrm{m}^{-2} \mathrm{~d}^{-1}$ ). In the absence of advective or predatory losses, primary production within patches was sufficient to support formation and persistence of discrete patches. However, additional processes such as vertical shear are required to enforce continued separation of water masses. Patches contributed the majority of depth-integrated water column primary production, making the study of patchiness an important topic for understanding and quantifying phytoplankton abundance, distribution, and production as well as food web and biogeochemical ramifications. These results extend prior findings documenting enhanced heterotrophic grazing in patches and suggest that phytoplankton patches are not only consumption but also production hot spots.
\end{abstract}

KEY WORDS: Photosynthesis-irradiance relationship · Patchiness · Phytoplankton · Primary production

\section{INTRODUCTION}

Plankton patchiness has long been described from a wide variety of environments (reviewed by Durham \& Stocker 2012). The mechanisms leading to plankton patch formation and maintenance are still unknown, with both biological and physical processes contributing to the phenomenon. Multiple mechanisms have been suggested to explain the formation and persistence of plankton patches, including concentration of cells in areas of neutral buoyancy (Franks 1992, Alldredge et al. 2002), vertical shear
(Franks 1995, Birch et al. 2009), and swimming behaviors interacting with fluid flow (Bjørnsen \& Nielsen 1991, Gallager et al. 2004, Genin et al. 2005, Durham et al. 2009). Aside from swimming behaviors, research into possible patch formation mechanisms has largely been dominated by investigations of physical processes. Biological processes, particularly in situ growth and mortality, remain a key knowledge gap.

Plankton population dynamics are likely fundamental components of patch formation (Abraham et al. 2000), and patches have long been suggested 
to function as 'trophic hot spots.' Grazing rates by heterotrophic protists feeding within phytoplankton patches were significantly higher than elsewhere in the water column, irrespective of phytoplankton abundance, lending empirical support for the 'trophic hot spot' hypothesis (Menden-Deuer \& Fredrickson 2010). Predator-induced mortality rates that are focused within phytoplankton patches and remove biomass could either prevent patch formation or enhance rates of patch decline. Therefore, the biologically driven dynamics of phytoplankton patches depend on the relative balance of phytoplankton growth and predator grazing rates. To date, empirical measurements of key trophic and demographic rates, particularly photosynthesis, production, and predator-induced mortality rates are rare. However, quantitative estimates of photosynthesis parameters are essential to assess the potential role of growth in driving patch formation and counterbalancing dispersive forces (Stacey et al. 2007).

Assessment of in situ primary production rates, especially with high temporal and spatial resolution, can be difficult. Several methodological approaches exist, including radioisotope incorporation, oxygen production, and light-dark bottle incubations (reviewed by Robinson et al. 2009). Although measurements of primary production rates are fundamental to oceanography, and developments of in situ measurements hold great promise (Kolber \& Falkowski 1993), no commonly accepted approach has been adopted due to artifacts imposed by either the incubation or underlying assumptions (Robinson et al. 2009). Most commonly, photosynthetic rates for diverse phytoplankton communities have been measured using the radioisotope method that was first developed by Steemann Nielsen (1952). The radioisotope technique exploits the fact that photosynthetic organisms incorporate inorganic $\mathrm{CO}_{2}$ to generate organic matter. The method is highly sensitive, and can be used to detect radioactive uptake within a single cell (e.g. MendenDeuer \& Lessard 2000). Since its invention, the radioisotope method has been effectively applied to measure phototrophic processes, including phytoplankton growth rates and carbon to chlorophyll $a$ (chl a) ratios (Welschmeyer \& Lorenzen 1984), heterotrophic protist grazing rates (Montagnes \& Lessard 1999), release of organic matter (Bochdansky et al. 2010), and cellular carbon content (Putt \& Stoecker 1989, Crawford \& Stoecker 1996).

Incubation-based measurements of photosynthesisirradiance response curves ( $P$ vs. $E$ ) of phytoplankton from both laboratory cultures and whole community assemblages have been used extensively to identify the functional relationship between photosynthesis and light intensity and to quantify the light-saturated, biomass-specific, maximum photosynthetic rate $\left(P^{B-}\right.$ $\max )$, the slope $(\alpha)$, which is the initial, light-limited slope of the $P$ vs. $E$ relationship, and $E_{k}$, the light saturation index, indicating the optimal irradiance for photosynthesis (Geider et al. 1997). The $P$ vs. $E$ coefficients in turn form the basis of primary production estimates, which also take into account the depth of the euphotic zone, ambient irradiance, and day length (Behrenfeld \& Falkowski 1997b).

It is now generally agreed that even short-term applications of the radioactive bicarbonate $\left(\mathrm{H}^{14} \mathrm{CO}_{3}\right.$ - $)$ labeling method measure net rather than gross primary production rates, accounting for autotrophic respiratory losses (Marra 2009). However, losses due to predation are often unknown in such incubations, which include heterotrophic respiration and herbivory. Protistan grazing accounts for, on average, more than $50 \%$ of primary production in the ocean (Calbet \& Landry 2004). This magnitude is comparable to largescale, overall production losses estimated based on satellite-derived data (Siegel et al. 2002), suggesting that measured phytoplankton losses largely represent grazing. The currently most common method of estimating protistan grazing rates is the dilution method (Landry \& Hassett 1982), which requires $24 \mathrm{~h}$ incubations of $\geq 1 \mathrm{l}$ of seawater, and considerable logistical effort in preparing the dilution series. The research presented here includes a modification of the $P$ vs. $E$ measurements to quantify the possible effect of herbivory on measured rates of primary production and to examine whether using radioactive bicarbonate, which can be measured with much greater sensitivity than the chl a tracer used in dilution experiments, would enable shorter incubations ( 2.5 versus $24 \mathrm{~h}$ ) and contribute a more rapid and less time-consuming assessment of protistan grazing.

The overall goal of this research was to quantify photosynthetic potential and primary production rates as a function of plankton patchiness in order to (1) identify whether primary production can contribute to patch formation and maintenance, and (2) estimate the contribution of patch primary production to depth-integrated water column production.

\section{MATERIALS AND METHODS}

\section{Field site}

East Sound is a temperate fjord in the northeastern Pacific $\left(48^{\circ} 38.61^{\prime} \mathrm{N}, 122^{\circ} 52.75^{\prime} \mathrm{W}\right)$, with a north- 
south extent of approximately $10 \mathrm{~km}$ and east-west width between 1 and $2 \mathrm{~km}$. Depth ranges from $<20 \mathrm{~m}$ at the northern end to $>40 \mathrm{~m}$ at the southern end. Exchange with the tidally well-mixed Harney Channel to the south is restricted by a partial sill at the southwestern terminus of the fjord. A longitudinal transect of 5 stations, including 1 station just outside East Sound, was regularly sampled. A map of the station locations is presented in Menden-Deuer (2008). Up to 3 sampling trips were carried out each week. A total of 29 day-cruises were conducted: 15 in 2007, 8 in 2008 and 6 in 2009. At each station, the water column was profiled with a SeaBird 19+ CTD mounted with a WetLabs WetStar fluorometer. In 2007, a hand-held light meter (Li-Cor, $\mathrm{LI}^{-1} 400$ ) with an underwater spherical quantum sensor (SPQA 3585) was used to acquire water column light profiles. After 2007, a SeaBird C-Star measuring beam transmission over $25 \mathrm{~cm}$ at $660 \mathrm{~nm}$ and a Biospherical QSP-2300L $4 \pi$ photosynthetically active radiation (PAR) sensor were added. Continuous measurements of surface irradiance were made with a Li-Cor LI-190SA Quantum sensor averaged for hourly intervals for the photoperiod between 06:00 and 21:00 h. The mean descent rate of the CTD was $0.2 \mathrm{~m} \mathrm{~s}^{-1}$, and the vertical resolution was $0.1 \mathrm{~m}$. Real-time measurements of water column profiles, including chl a-induced fluorescence, were displayed shipboard and used to identify the presence and depth of distinct patches.

Patches were defined as distinct concentrations of chl a-induced fluorescence that locally exceeded overall water column fluorescence by at least 3-fold. Patches could extend vertically over several meters, so long as a distinct difference existed between an inside and outside signal. Examples of patchy and non-patchy profiles are shown in Fig. 1. Note that patchiness was not a function of total fluorescence, as both high and low fluorescence profiles could be identified as non-patchy samples. A 21 horizontally mounted Niskin bottle was used to capture water samples from distinct depths (Menden-Deuer 2008). Sampling depths were determined using an adaptive sampling scheme based on real-time water column profiles. When distinct patches were present in the chl a fluorescence profiles (Fig. 1, top), water samples were collected from 2 depths, one within the fluorescence maximum, hereafter termed 'inside,' and the other $2 \mathrm{~m}$ shallower or deeper, hereafter termed 'outside.' Profiles lacking distinct structure in chl ainduced fluorescence profiles (Fig. 1, bottom) were sampled at a reference depth of $5 \mathrm{~m}$. The samples were stored dark and cooled during the 45 min transport to the laboratory.

\section{Photosynthesis-irradiance curves}

Photosynthesis-irradiance $(P$ vs. $E)$ curves were established in temperature-controlled light gradient boxes, using the radioisotope labeling method (Steemann Nielsen 1952). Depending on the abundance of phytoplankton, between 10 and $40 \mu \mathrm{l}$ of

${ }^{14} \mathrm{C}$-labeled sodium bicarbonate, $\mathrm{NaH}^{14} \mathrm{CO}_{3}$ (Moravek Biochemicals) with a specific activity of $250 \mu \mathrm{Ci}$ $\mathrm{ml}^{-1}$ were added to $120 \mathrm{ml}$ of whole seawater prefiltered through a $200 \mu \mathrm{m}$ mesh net to eliminate mesozooplankton grazers. Each $120 \mathrm{ml}$ sample represented a unique station or depth. Triplicate $0.1 \mathrm{ml}$ sub-samples from each sample measured average initial activity. A subset of $P$ vs. $E$ experiments was incubated in triplicate to estimate methodological variation of parameter estimates. Aliquots $(8 \mathrm{ml})$ of the $120 \mathrm{ml}$ samples were transferred to $20 \mathrm{ml}$ glass scintillation vials: 14 light and 1 dark. Each $8 \mathrm{ml}$ plankton sample was incubated for $2.5 \mathrm{~h}$ at a light intensity gradient ranging from 0 to $1400 \mu \mathrm{mol}$ photons $\mathrm{m}^{-2} \mathrm{~s}^{-1}$. The scintillation vials were placed in a temperature-controlled light box illuminated by a $250 \mathrm{~W}$ metal halide lamp (Hubbel) (Oviatt et al. 2007). Temperature was set to $12^{\circ} \mathrm{C}$, the average in situ temperature. The 15 vials were incubated across the range of light intensities, with at least 5 samples at $<200 \mu \mathrm{mol}$ photons $\mathrm{m}^{-2} \mathrm{~s}^{-1}$. There was no replication of individual light intensities. The goal of spreading samples across light intensities with an emphasis on low light intensities was to increase statistical confidence in the $P$ vs. $E$ curve parameters, particularly the slope (Montagnes \& Berges 2004). Incubations were terminated by acidifying samples with $1 \mathrm{ml}$ of $1 \mathrm{~N} \mathrm{HCl}$ and allowing inorganic ${ }^{14} \mathrm{C}$ to outgas for $24 \mathrm{~h}$. Samples were neutralized with $1 \mathrm{ml}$ of $1 \mathrm{~N} \mathrm{NaOH}$ and received $8 \mathrm{ml}$ scintillation cocktail (Ecoscint XR, National Diagnostics). Decays per minute (dpm) were measured in a Packard 1900 TR scintillation counter. The importance of incubation time on parameter estimates was examined by performing identical procedures as described above but varying the incubation duration from 2 to $6 \mathrm{~h}$.

\section{Protistan grazing impact}

To examine the effect of protistan grazing impact on primary production and to test the possibility of using this approach as an alternate technique to measure grazing, I incubated whole seawater samples diluted with $0.2 \mu \mathrm{m}$ filtered seawater in analogy 


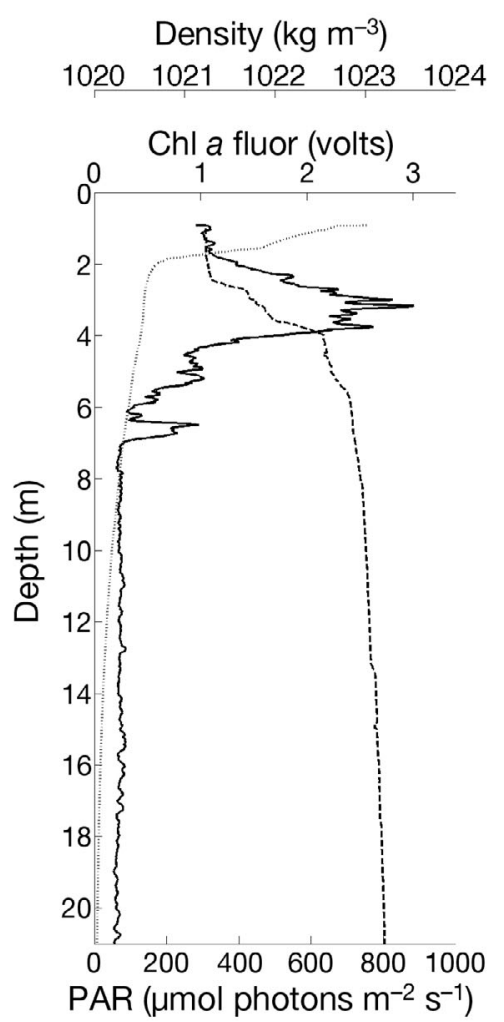

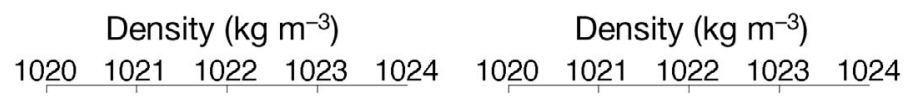
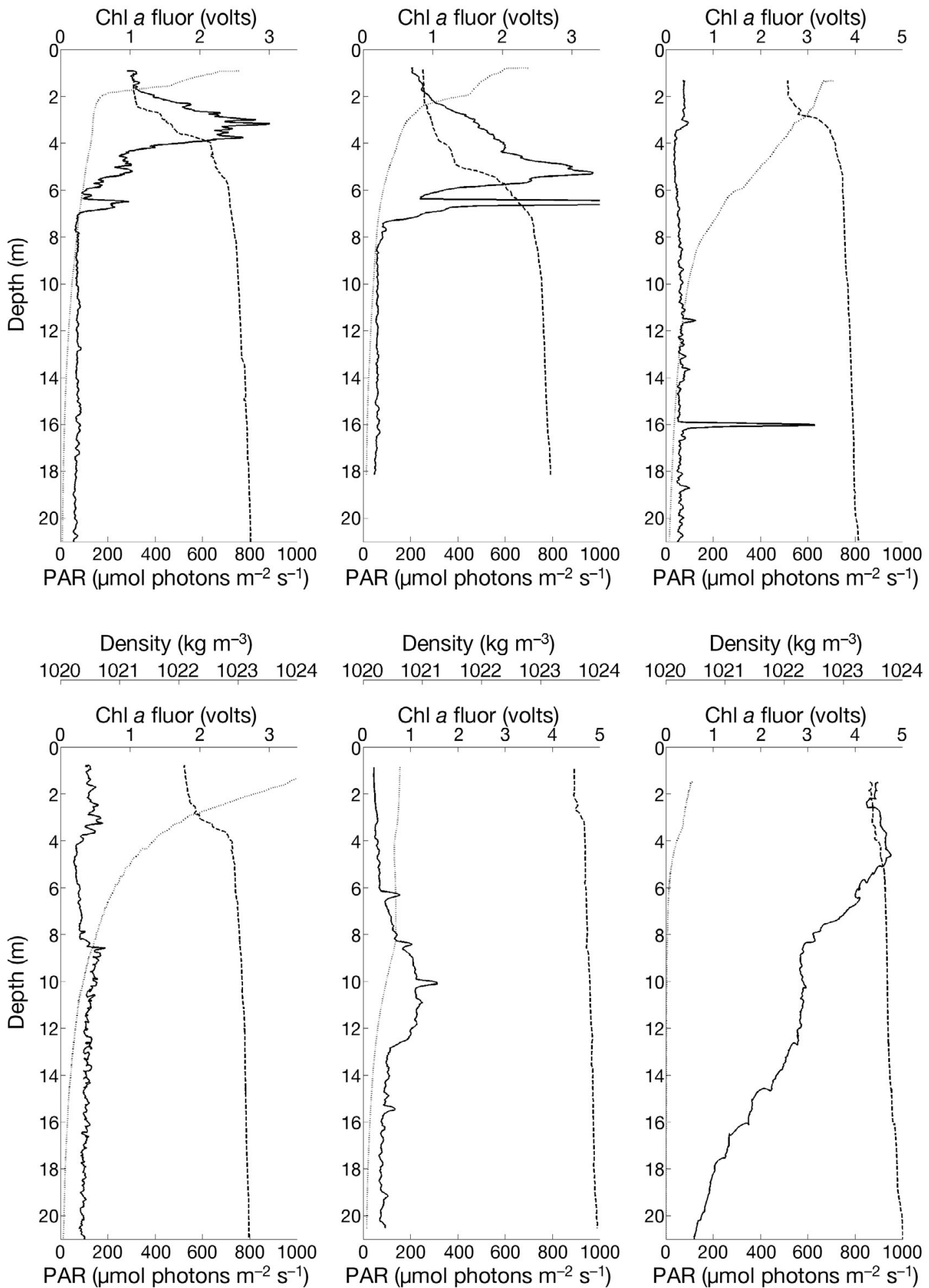

\begin{tabular}{llll}
\multicolumn{5}{c}{ Density $\left(\mathrm{kg} \mathrm{m}^{-3}\right)$} \\
$1020 \quad 1021$ & 1022 & 1023 & 1024
\end{tabular}
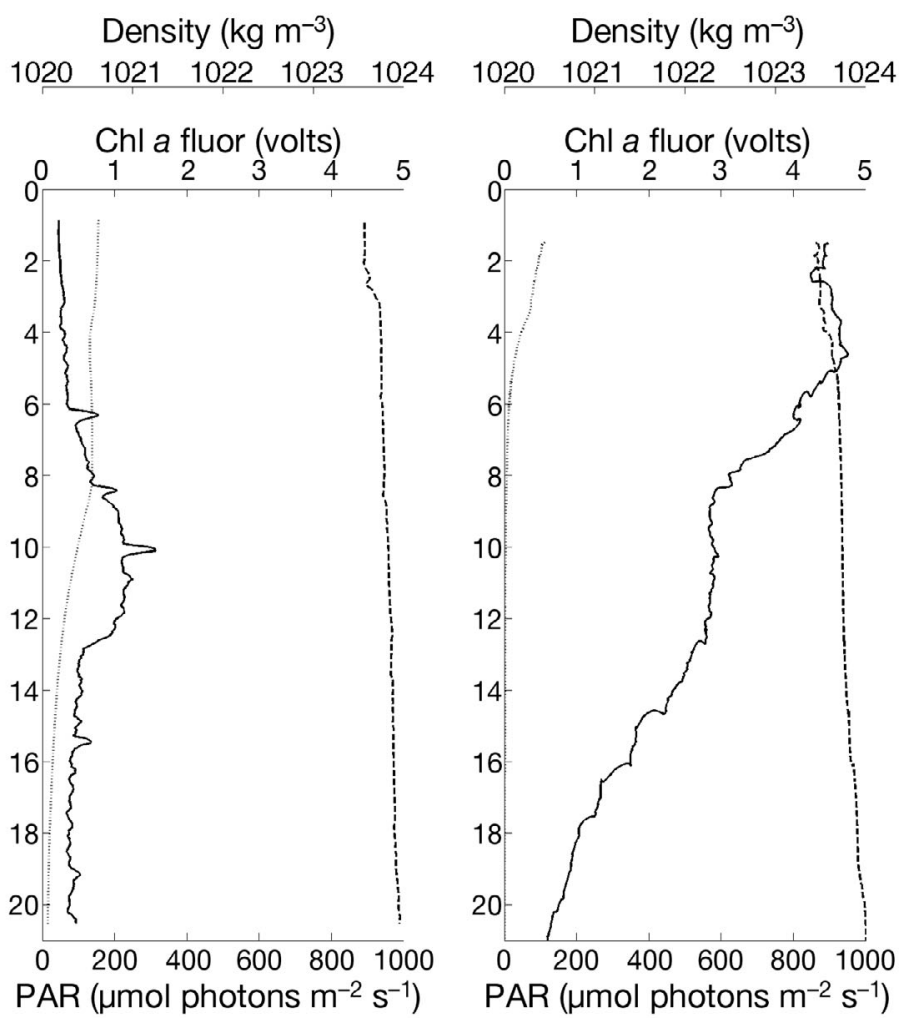

Fig. 1. Vertical profiles of seawater density $\left(\mathrm{kg} \mathrm{m}^{-3}\right.$; thick dashed line), chlorophyll a (chl a)-induced fluorescence (volts; solid

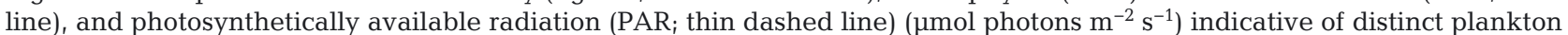
patches (top row) and lacking distinct patchiness (bottom row). Note change in chl a unit ranges 
to the dilution method (Landry \& Hassett 1982). Ten water samples, at 4 to 6 dilution levels each, ranging from 10 to $100 \%$ whole seawater, were prepared for each water sample and then treated as described in the previous section for $P$ vs. $E$ curve measurements. The principal differences between the approach used here and the standard procedures for the dilution technique were that the incubation volumes were smaller $(10 \mathrm{ml})$ and the incubation duration shorter $(2.5 \mathrm{~h})$ than for standard dilution experiments where volumes typically exceed 11 and incubations are terminated after $24 \mathrm{~h}$.

\section{Simulated in situ productivity}

In 2007, productivity measurements were made using simulated in situ conditions to facilitate comparison with the small-volume $P$ vs. $E$ incubations described in 'Photosynthesis-irradiance curves'. Whole seawater samples were captured and treated as for the $P$ vs. $E$ incubations. Whole seawater was added to each of 6 clear, $170 \mathrm{ml}$ polycarbonate bottles and spiked with $30 \mu \mathrm{Ci} \mathrm{ml}{ }^{-1}{ }^{14} \mathrm{C}$-labeled sodium bicarbonate. One bottle from each sixtuplet was selected, inverted 10 times and $100 \mu \mathrm{l}$ samples withdrawn to determine initial total activity. Bottles were covered with 1 to 5 layers of neutral-density mesh screen, each screen successively reducing light available by $50 \%$. The sixth sample was placed in a black plastic bag to serve as the dark control for light-independent uptake of radio-labeled sodium bicarbonate. All bottles were incubated on a rotating wheel for $2.5 \mathrm{~h}$ at ambient temperature and irradiance. To terminate the incubation, the volume within each bottle was filtered on a GF/F filter and placed in a $20 \mathrm{ml}$ plastic scintillation vial, and remaining inorganic radiolabeled sodium bicarbonate was driven off through acidification with $0.5 \mathrm{ml}$ of $1 \mathrm{~N} \mathrm{HCl}$. Samples were outgassed for at least $12 \mathrm{~h}$ and neutralized with 0.5 $\mathrm{ml}$ of $1 \mathrm{~N} \mathrm{NaOH}$. Scintillation cocktail (Ecoscint LS271, National Diagnostics; $6 \mathrm{ml}$ ) was added to each scintillation vial. The samples were then processed as described in 'Photosynthesis-irradiance curves' for the photosynthetron $P$ vs. $E$ curves. The goal of these larger volume incubations was to assess whether the larger number of light levels, constant incubation temperature, lack of rotation, artificial irradiance, and smaller volumes used with the photosynthetron incubations provided $P$ vs. $E$ coefficients comparable to this larger volume, simulated in situ method.

\section{Calculations and statistical analysis}

The measured dpm were dark-corrected for lightindependent uptake of ${ }^{14} \mathrm{C}$, converted to volumespecific productivity rates $\left(\mu \mathrm{g} \mathrm{C} \mathrm{ml} \mathrm{C}^{-1} \mathrm{~h}^{-1}\right)$, and then normalized to chl a concentration, the measured proxy for phytoplankton biomass, which yielded photosynthesis rates as mg C (mg chl a $)^{-1} \mathrm{~h}^{-1}$ following Parsons et al. (1984). The independent variable, light intensity, had units of $\mu \mathrm{mol}$ photons $\mathrm{m}^{-2} \mathrm{~s}^{-1}$. An isotope discrimination factor of 1.05 was assumed to account for the preferential uptake of ${ }^{12} \mathrm{C}$ fractionation (Strickland \& Parsons 1972). The resulting estimates of photosynthesis rates at the appropriate irradiance were fit to a hyperbolic tangent function using a non-linear curve fit in MatLab R 7.10 following Eq. (8) in Jassby \& Platt (1976):

$$
P^{B}(E)=P_{\text {max }}^{B} \tanh \left(\alpha E / P_{\text {max }}^{B}\right)
$$

with maximum chl a specific carbon fixation rate $P^{B}{ }_{\text {max }}\left[\mathrm{mgC}(\mathrm{mg} \mathrm{chl} a)^{-1} \mathrm{~h}^{-1}\right]$, light utilization coefficient $\alpha$ [mgC (mg chl a $)^{-1} \mathrm{~h}^{-1}$ ( $\mathrm{mmol}$ photons $\mathrm{m}^{-2}$ $\left.\mathrm{s}^{-1}\right)^{-1}$ ], and $E$ irradiance ( $\mu \mathrm{mol}$ photons $\mathrm{m}^{-2} \mathrm{~s}^{-1}$ ). The non-linear, least squares regression yielded the photosynthetic parameters, as well as their respective goodness of fit measures, significance levels, confidence intervals, and the overall correlation coefficient. Thus, for all coefficients and the overall curve fit, the reliability of the estimate was calculated. Only $P$ vs. $E$ coefficients resulting from significant regressions are presented. The light saturation index $E_{k}$ was calculated from the ratio of maximum photosynthesis rate and light utilization $E_{k}=P_{\text {max }}^{B} / \alpha$. Previous analyses have found the Jassby \& Platt (1976) model to have lower \% standard error compared to the model of Webb et al. (1974) because the quadratic approximation has higher precision in the mathematical solution (Frenette et al. 1993). The model used does not assume photoinhibition (Platt et al. 1980), as none of the measurements made indicated photoinhibition as would have been suggested by a decrease in photosynthetic rate at higher irradiance.

A total of 27 large-volume, simulated in situ productivity measurements were made. Of these, 1 sample showed no significant uptake of ${ }^{14} \mathrm{C}$ relative to the background, and 1 sample showed a linear, nonsaturating increase in radio-carbon uptake with increasing light level. Both samples were eliminated from the analysis. Ten samples were run in dilutions between 10 and $100 \%$ whole seawater to test the possibility of using $P$ vs. $E$ measurements to quantify grazing impact of heterotrophic protists on phytoplankton abundance and productivity. 
Depth-specific, volume-normalized primary production rates $\left(P^{B}\right)$ were calculated using 2 different light intensities (Behrenfeld \& Falkowski 1997b). First, primary production was calculated using the instantaneous, in situ light intensity measured at sampling time and depth. Second, to eliminate the effect of short-term variability in light intensity, primary production was calculated based on the average depth-adjusted surface irradiance measured over the 3 to $4 \mathrm{~h}$ sampling period. The averaged irradiance is the more conservative estimate and less subject to short-term variations and thus a more reliable predictor of primary production. Irradiances at sampling depth were calculated based on the water column specific attenuation coefficient, $k\left(\mathrm{~m}^{-1}\right)$, the slope of the least-squares regression of the natural log of light intensity versus depth. Spectral composition changes with depth were not included in this comparison (Behrenfeld \& Falkowski 1997a). Inclusion of a wavelength-resolved approach would result in a slight increase in primary production at shallower depths and would further support the conclusions. Daily vertically integrated primary production (mg C m${ }^{-2} \mathrm{~d}^{-1}$ ) over the $16 \mathrm{~h}$ light period was calculated by multiplying the depth-specific, volumenormalized primary production rates by the depthspecific chl a concentration and integrating over the euphotic zone down to the $1 \%$ surface irradiance, $20 \mathrm{~m}$ depth. Integrated primary production rates presented here are based on averaged chl a and irradiance profiles collected in July 2007. Continuous water column profiles of chl a were established by converting the in situ, CTD-mounted fluorometermeasured fluorescence signal to chl a concentrations based on extracted chl a measurements that were taken to calibrate the fluorometer signal. Chl a extraction in acetone followed the procedures of Graff \& Rynearson (2011). The resulting chl a calibration was in excellent agreement with a previously established calibration of the continuous fluorescence signal with chl a using the same instrument and procedures (Menden-Deuer 2008). Since signifi- cant differences in primary productivity rates for patch versus non-patch phytoplankton were found, the structure-specific rates were applied to the respective depth of the water column (i.e. in-patch rates for patches, non-patch rates outside patches).

Normality of data was assessed using the ShapiroWilks test. Non-normally distributed data were transformed using a square root or natural log transform before analysis. Two-way analysis of variance (ANOVA) was used to identify relationships between sample station or depth and to determine whether $P$ vs. $E$ parameters of plankton patch communities departed significantly from all others. The sample size for the ANOVA was $94 P$ vs. $E$ curves. A paired $t$-test was used to compare $P$ vs. $E$ parameters from within-patch communities specifically to those captured on the same day and station, at an adjacent depth either above or below the patch. The samples size for the paired, 2-tailed $t$-test was 28, i.e. 14 samples each inside and outside of patches. Statistical significance was assigned at $\mathrm{p}<0.05$, and a Bonferroni correction was applied when multiple comparisons were made.

\section{RESULTS}

\section{Characteristics of $\boldsymbol{P}$ vs. $\boldsymbol{E}$ parameters}

The $P$ vs. $E$ parameters reported here represent a taxonomically diverse set of plankton communities from both summer and spring seasons, ranging from surface samples to $14 \mathrm{~m}$ depth and chl a concentrations from 0.6 to $26.6 \mu \mathrm{g}^{-1}$. Based on all $P$ vs. $E$ curves, the average photosynthetic efficiency $(\alpha)$ was $0.013 \mathrm{mg} \mathrm{C}(\mathrm{mg} \mathrm{chl} \mathrm{a})^{-1} \mathrm{~h}^{-1}\left(\mu \mathrm{mol} \text { photons } \mathrm{m}^{-2} \mathrm{~s}^{-1}\right)^{-1}$ with a range from 0.002 to 0.037 , and the average maximum photosynthesis rate, $P_{\text {max }}^{B}$, was $3.80 \mathrm{mg} \mathrm{C}$ $(\mathrm{mg} \mathrm{chl} \mathrm{a})^{-1} \mathrm{~h}^{-1}$ with a range from 1 to 12 (Table 1$)$. The average light saturation index $\left(E_{k}\right)$ was $391 \mu$ mol photons $\mathrm{m}^{-2} \mathrm{~s}^{-1}$ with a range from <100 to 1090 . There were no statistically significant associations of

Table 1. Mean \pm SE values for $P$ vs. $E$ coefficients for all samples combined and during each sampling season separately. Sample size (n) indicates how many independent $P$ vs. $E$ curves were measured, at 15 light levels each. Note that $\alpha$ and SE values for $\alpha$ are $\times 10^{-3}$

\begin{tabular}{|c|c|c|c|c|c|}
\hline Sampling time & $\begin{array}{c}\text { Chl a } \\
\left(\mu g l^{-1}\right)\end{array}$ & $\begin{array}{c}P^{B}{ }_{\max } \\
\operatorname{mgC}(\operatorname{mg} \operatorname{chl} a)^{-1} \mathrm{~h}^{-1}\end{array}$ & $\begin{array}{c}\alpha\left[\mathrm{mg} \mathrm{C}(\mathrm{mg} \mathrm{chl} \mathrm{a})^{-1} \mathrm{~h}^{-1}\right. \\
\left.\left(\mu \mathrm{mol} \text { photons m} \mathrm{m}^{-2} \mathrm{~s}^{-1}\right)^{-1}\right] \times 10^{-3}\end{array}$ & $\begin{array}{c}E_{k}(\mu \mathrm{mol} \\
\left.\text { photons } \mathrm{m}^{-2} \mathrm{~s}^{-1}\right)\end{array}$ & $\mathrm{n}$ \\
\hline All years & $6.32 \pm 0.55$ & $3.80 \pm 0.19$ & $12.62 \pm 0.80$ & $391 \pm 24$ & 94 \\
\hline Summer 2007 & $4.86 \pm 0.51$ & $4.01 \pm 0.25$ & $7.90 \pm 0.55$ & $556 \pm 33$ & 50 \\
\hline Summer 2008 & $7.56 \pm 0.91$ & $3.65 \pm 0.49$ & $18.15 \pm 1.57$ & $210 \pm 20$ & 23 \\
\hline Spring 2009 & $8.47 \pm 1.90$ & $3.41 \pm 0.34$ & $17.91 \pm 1.71$ & $226 \pm 37$ & 21 \\
\hline
\end{tabular}


$P$ vs. E parameters with sampling stations or depth. All $P$ vs. $E$ parameters varied significantly over time ( $p \leq 0.03$ ). The photosynthetic efficiency in 2007 was less than half the efficiency in both 2008 and 2009, and the light saturation index was approximately 2fold higher (Table 1). The similarity in coefficients between 2008 and 2009 was observed despite the fact that plankton samples were taken in different seasons. Temporal differences were not associated with specific events or phytoplankton communities; there was no significant correspondence in magnitude of any $P$ vs. E parameter to a particular environmental or biological factor, including community composition.

The $P$ vs. $E$ model yielded highly significant fits of the overall $P$ vs. $E$ curve $(\max \mathrm{p}=0.006)$ as well as the individual coefficients. The maximum $p$-values observed for $\alpha$ and $P^{B}$ max were $\mathrm{p}=0.03$ and $\mathrm{p}=0.01$, respectively. Variations in $P$ vs. $E$ parameters among triplicate incubations suggest an inherent variation of $\sim 10$ to $20 \%$ (Table 2 ). The coefficients of variation (i.e. $\mathrm{SD} /$ mean $\times 100$ ) were 19,7 , and $24 \%$ for $\alpha, P_{\text {max }}^{B}$ and $E_{k}$, respectively. There were no significant correlations between $P$ vs. $E$ coefficients and ambient nutrient concentrations, with the exception of a significant $(\mathrm{p}<0.001)$ but weak association between $\alpha$ and silicic acid concentrations $\left(r^{2}=0.20\right)$. Details on nutrient measurements and concentrations are provided elsewhere (Menden-Deuer \& Fredrickson 2010).

Incubation duration did not significantly affect $P$ vs. $E$ estimates. Irrespective of incubation duration between 2 and $6 \mathrm{~h}$, a significant relationship between irradiance and photosynthetic rate was observed; all parameter estimates were significant $(\max \mathrm{p}<0.002$ and $r^{2}$ values $\left.>0.85\right)$. Estimates of $\alpha, P^{B}{ }_{\max }$ and $E_{k}$ coefficients did not vary significantly as a function of incubation duration, and the maximum coefficients of variation were 15,9 , and $5 \%$, respectively, similar to the variation among replicates.

Table 2. $P$ vs. E coefficients from triplicate measurements of photosynthesis rate across a gradient in light intensity $(\mu \mathrm{mol}$ photons $\mathrm{m}^{-2} \mathrm{~s}^{-1}$ ). Replication yielded coefficients of variation (\%), an estimate of among-incubation variation. Units are as in Table 1

\begin{tabular}{|lccc|}
\hline Replicate & $\alpha \times 10^{-2}$ & $P^{B}{ }_{\max }$ & $E_{\mathrm{k}}$ \\
\hline 1 & 2.44 & 4.59 & 188 \\
2 & 2.06 & 4.35 & 212 \\
3 & 1.67 & 4.95 & 296 \\
$\mathrm{CV}$ & 18.7 & 6.5 & 24.4 \\
\hline
\end{tabular}

\section{Association of $\boldsymbol{P}$ vs. $\boldsymbol{E}$ parameters with patchiness}

To determine whether plankton patches had significantly higher photosynthetic potential, $P$ vs. $E$ coefficients from inside and outside plankton patches were compared. The targeted comparison of photosynthesis parameters of whole plankton communities collected from both inside and outside patches at the same station showed that plankton communities from inside plankton patches had significantly higher photosynthetic potential than communities captured outside plankton patches, with higher $P^{B}{ }_{\text {max }}(p=0.01)$ and $\alpha(p=0.03)$ values (Fig. 2, Table 3$)$. Although the light saturation index, $E_{k}$, also suggested that lower irradiance was necessary to saturate photosynthesis for phytoplankton from within patches, the difference was not statistically significant ( $p=0.81)$. Overall, samples captured inside a patch at a particular station showed higher photosynthetic potential than samples captured outside, either above or below patches. Because these samples were taken in the field, according to the conditions found, there was a potentially confounding effect in that most patch samples were taken at a shallower depth than outside samples. Thus, an overall patch distribution at shallower depths may have resulted in a biased sampling of patch versus non-patch samples. Average \pm SE PAR of patch samples was $209 \pm 32 \mu \mathrm{mol}$ photons $\mathrm{m}^{-2} \mathrm{~s}^{-1}$ and $225 \pm 121$ for outside samples (Table 3 ). As the higher variability associated with PAR of outside samples shows, outside samples were sampled both above, with higher surface irradiances up to $1600 \mu \mathrm{mol}$ photons $\mathrm{m}^{-2} \mathrm{~s}^{-1}$, and below patches, at PAR levels as low as $9 \mu \mathrm{mol}$ photons $\mathrm{m}^{-2} \mathrm{~s}^{-1}$. A separate analysis of only those samples for which inside patch samples were taken deeper than the 'outside'

Table 3. Comparison of $P$ vs. $E$ coefficients and error estimates for plankton samples taken on the same date and at the same station from depths either inside $(n=14)$ or outside $(\mathrm{n}=14)$ phytoplankton patches. Standard errors are given in parentheses, units for coefficients are stated in Table 1; photosynthetically active radiation (PAR) was measured as $\mu \mathrm{mol}$ photons $\mathrm{m}^{-2} \mathrm{~s}^{-1} . P$ vs. $E$ coefficients for samples from inside plankton patches were significantly higher than for outside patch samples, and are indicated by $\left({ }^{*}\right)$

\begin{tabular}{|lcccc|}
\hline & $P^{B}{ }_{\max }$ & $\alpha$ & $E_{k}$ & PAR (in situ) \\
\hline Inside patch & $3.26^{*}$ & $0.010^{*}$ & 372 & 209 \\
& $(0.38)$ & $(0.002)$ & $(52)$ & $(32)$ \\
Outside patch & 2.48 & 0.007 & 486 & 225 \\
& $(0.33)$ & $(0.001)$ & $(63)$ & $(121)$ \\
\hline
\end{tabular}


control sample showed that maximum biomassspecific photosynthesis rate, even for these deeper, inside patch samples was between 9 and $33 \%$ higher than the shallower 'outside' samples. Mean sampling depth for inside samples was $4 \mathrm{~m}$ compared to 0.5 to $2 \mathrm{~m}$ for outside samples. Photosynthesis rates for these inside patch samples were higher, even though ambient irradiance was lower at the deeper depth. Therefore, although the generally shallower patch sampling depth did contribute to the higher photosynthesis rates measured inside patches, likely due to acclimation, there was a measurable intrinsically higher photosynthetic capacity for patch-associated phytoplankton.

Broadening the above comparison of $P$ vs. $E$ parameters for all samples collected over the 3 seasons, and including samples from non-patchy water column profiles, suggested that patch plankton communities did not have an overall, intrinsically higher photosynthetic potential. There was a total of 94 samples: 48 non-patch, 32 inside, and 14 outside patch samples. There was no significant difference among $P$ vs. $E$ coefficients for inside patch, outside, and non-patch samples (Fig. 3). Average \pm SE irradiance was similar for all 3 sample types, with inside, outside, and homogenous samples captured at $191 \pm 25,225 \pm 121$, and $220 \pm 31 \mu \mathrm{mol}$ photons $\mathrm{m}^{-2} \mathrm{~s}^{-1}$. This indicates that phytoplankton communities from inside plankton patches were not inherently distinguishable by an overall higher photosynthetic potential or capacity than the phytoplankton communities observed throughout the sampling period and under diverse environmental and biological conditions.

\section{Simulated in situ productivity measurements}

Larger volume, simulated in situ productivity measurements were made to provide comparisons among rates gathered with the smaller volume, photosynthetron method. Average PAR of all samples gathered for this comparison was $211 \pm 41 \mu \mathrm{mol}$ photons $\mathrm{m}^{-2} \mathrm{~s}^{-1}$. The simulated in situ productivity incu-
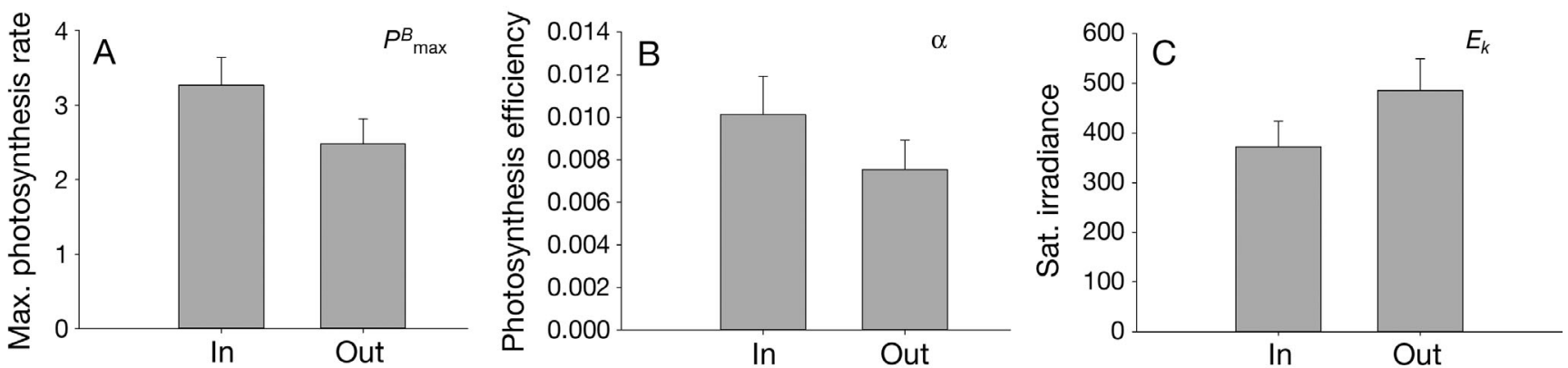

Fig. 2. Average (+SE) $P$ vs. E coefficients for phytoplankton communities drawn from inside and outside plankton patches (n = 28) within the same water column. Units for $y$-axes are: (A) $P^{B}{ }_{\max }\left[\mathrm{mg} \mathrm{C}(\mathrm{mg} \mathrm{chl} \mathrm{a})^{-1} \mathrm{~h}^{-1}\right],(\mathrm{B}) \alpha\left[\mathrm{mg} \mathrm{C}^{-}(\mathrm{mg} \mathrm{chl} a)^{-1} \mathrm{~h}^{-1}(\mu \mathrm{mol}\right.$ photons $\left.\mathrm{m}^{-2} \mathrm{~s}^{-1}\right)^{-1}$, and $(\mathrm{C})$ the light saturation index $E_{k}\left(\mu \mathrm{mol}\right.$ photons $\mathrm{m}^{-2} \mathrm{~s}^{-1}$ ). Plankton communities from within patches had significantly higher maximum photosynthetic rates $(p=0.01)$ and photosynthetic efficiencies $(p=0.03)$, but no difference was observed for $E_{k}(p=0.81)$
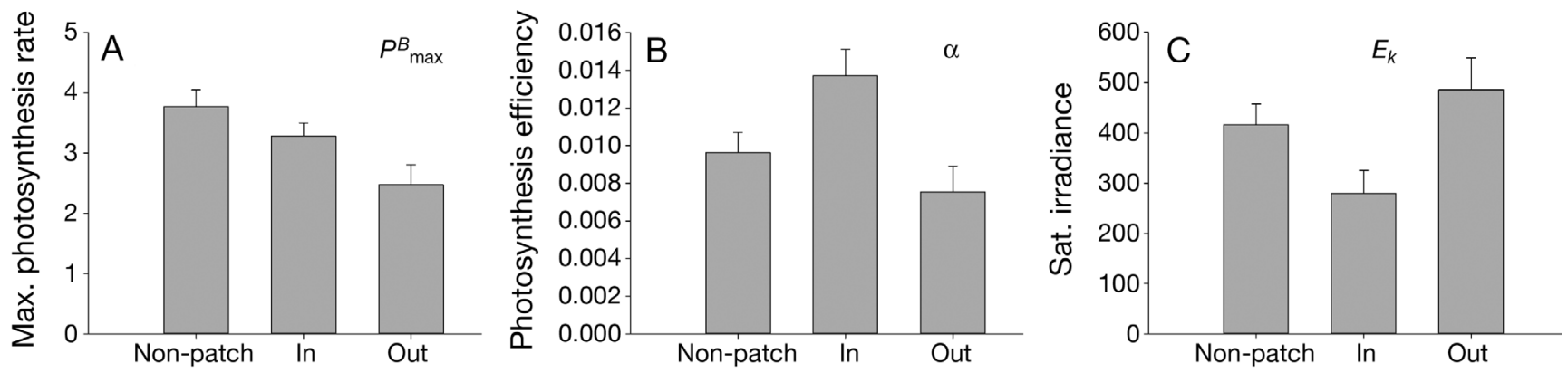

Fig. 3. Average (+SE) Pvs. E coefficients for phytoplankton communities drawn from inside plankton patches (In) compared to samples taken at the same station, outside patches (Out), and at stations without plankton patchiness (Non-patch). Units as in Fig. 2. Patch-associated plankton communities had higher, but not statistically significantly different, photosynthetic potential, due to higher $\alpha$ and lower $E_{k}$ values than communities from non-patchy phytoplankton distributions or those sampled outside patches 
bations, based on 6 light levels including the dark control, yielded significant estimates of all $P$ vs. $E$ parameters $(\mathrm{p}<0.02)$. The average photosynthetic efficiency $(\alpha)$ was $7.18 \times 10^{-3} \mathrm{mgC}(\mathrm{mg} \mathrm{chl} \mathrm{a})^{-1} \mathrm{~h}^{-1}$ ( $\mu$ mol photons $\left.\mathrm{m}^{-2} \mathrm{~s}^{-1}\right)^{-1}$, and the average maximum photosynthesis rate $\left(P^{B}{ }_{\max }\right)$ was $3.07 \mathrm{mgC}(\mathrm{mg}$ chl $a)^{-1} \mathrm{~h}^{-1}$. The average light-saturation index $E_{k}$ was $411 \mu \mathrm{mol}$ photons $\mathrm{m}^{-2} \mathrm{~s}^{-1}$ (Table 4 ).

Both the simulated in situ productivity measurements and the smaller volume photosynthetron incubations yielded statistically significant non-linear curve fits with low residual errors, with average $\mathrm{r}^{2}=$ 0.97 for the simulated in situ method and $\mathrm{r}^{2}=0.89$ for the photosynthetron method. There were no significant differences in $P$ vs. $E$ coefficient parameter estimates for any of the samples, irrespective of whether estimates were based on the large-volume in situ incubations or the smaller volume photosynthetron incubations $(p>0.05)$.

\section{$P$ vs. $E$ curves \\ to determine protistan grazing rate}

The radioisotope method combined with the dilution technique aimed to measure protistan grazing to examine the possibility of simultaneously measuring predator-induced phytoplankton mortality and growth rates. Serial dilution of radio-labeled samples to measure grazer-induced loss rates was not successful. Dilution, and thus manipulation of the predator-prey encounter rate, had no apparent effect on measured photosynthetic rate. Photosynthetic rate increased linearly with increasing phytoplankton concentration (i.e. dilution fraction), and biomassadjusted rates were constant across dilution fractions (Fig. 4). None of the experiments showed the expected, negative correlation between phytoplankton growth rate and concentration indicative of herbivory. For all dilution- $P$ vs. $E$ experiments, there was either no relationship or there was a significant, positive, and linear correlation between increasing dilution fraction and both photosynthetic efficiency as well as maximum photosynthetic rate (minimum $\left.\mathrm{r}^{2}=0.68\right)$. The observed positive correlation ran opposite to the expected and widely documented trend (Landry \& Hassett 1982): phytoplankton mortality decreases with decreasing dilution fraction because the encounter rate between predator and prey decreases and thus, predator-induced phytoplankton mortality rates decrease. These results indicate that in these $P$ vs. $E$ experiments, target dilutions were achieved and that photosynthesis
Table 4. Comparison of mean (SE) $P$ vs. $E$ coefficients from 2 independent methods: estimates from 19 samples determined with both simulated in situ incubations of $170 \mathrm{ml} \mathrm{sam-}$ ples at 6 light intensities and from incubations in a photosynthetron of $8 \mathrm{ml}$ samples at 15 light intensities. Units for coefficients are stated in Table 1. $P$ vs. E coefficients for both methods were statistically indistinguishable

\begin{tabular}{|lccc|}
\hline$P$ vs. E coefficient & $P^{B}{ }_{\max }$ & $\alpha \times 10^{-3}$ & $E_{k}$ \\
\hline Simulated in situ & $3.07(1.32)$ & $7.18(0.49)$ & $411(40)$ \\
Photosynthetron & $2.92(1.17)$ & $6.34(0.62)$ & $494(40)$ \\
\hline
\end{tabular}

rates were unaffected by dilution level, but that the significant grazing that was measured elsewhere on the same source water samples (see Menden-Deuer \& Fredrickson 2010) was not recorded with the combined radioisotope and dilution method. Therefore, dilution simply reduced the total biomass of phytoplankton within the incubation but not their net survival rates. Furthermore, this test also shows that observed photosynthetic rates were not affected by phytoplankton concentration within an order of magnitude, which means that photosynthetic performance was not reduced by competition for resources as a limiting factor.

Dilution of whole seawater samples resulted in low total chl a concentration at dilution levels of 10 to $30 \%$. Six of the 63 dilution- $P$ vs. $E$ curves did not

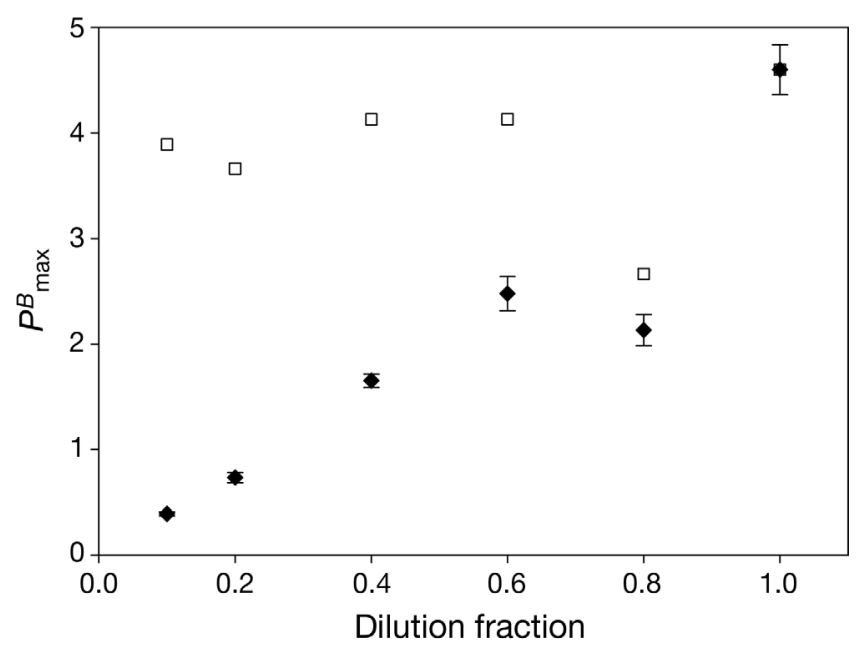

Fig. 4. Maximum photosynthetic rate $P^{B}$ max measured in a serial dilution of whole plankton samples $(\bullet)$ and biomassnormalized rates $(\square$, mean $\pm \mathrm{SE}) . P^{B}{ }_{\max }$ from dilution and biomass-normalized rates coincide at the $100 \%$ level. Biomass-normalized photosynthesis parameters were constant across dilution levels, irrespective of the gradient in predator-prey encounter rates, suggesting that predator-induced phytoplankton mortality did not alter the measured photosynthesis rates 
yield statistically significant fits to the $P$ vs. $E$ model of Jassby \& Platt (1976), 4 of which came from the same source sample. It is noteworthy that, with the exception of this one dilution series, $>90 \%$ of the incubations did yield statistically significant $P$ vs. $E$ curves, including samples with low initial chl a concentrations of $<1 \mu g \mathrm{l}^{-1}$, suggesting that this is a suitable method to apply even when chl a concentrations are low.

\section{In situ irradiance suggests light limitation}

The average attenuation coefficient of all light profiles was $k=0.23 \mathrm{~m}^{-1}$, with a range from 0.18 to 0.29 . Comparison of the in situ irradiance at the time of sampling with the $P$ vs. E-derived light saturation indices showed that $80 \%$ of the samples were exposed to irradiance levels below the light saturation index (Fig. 5). Patch phytoplankton were inconspicuous amongst this set and were found both above and below saturation irradiance levels as frequently as non-patch communities. Analysis of the $E_{k} /$ in situ PAR ratio suggested that light limitation was significantly greater $(p<0.001)$ in summer 2007 than either summer 2008 or spring 2009.

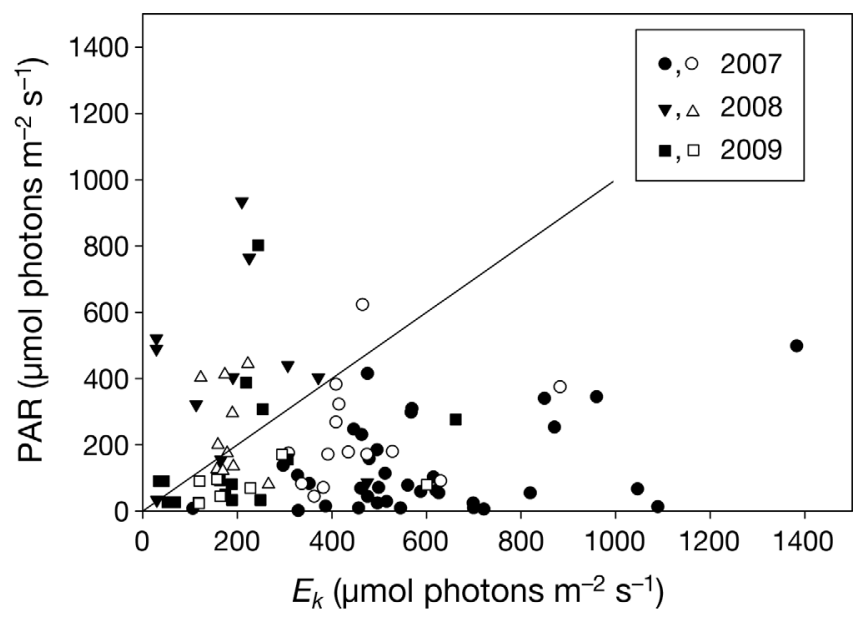

Fig. 5. Light-saturation indices $\left(E_{k}\right)$ calculated from $P$ vs. $E$ coefficients relative to photosynthetically active radiation (PAR) measured in situ at sampling depths. Samples are distinguished by year and whether samples were captured inside (open symbols) or outside of patches (closed symbols). Solid line indicates the 1:1 relationship, with samples taken at PAR irradiance levels exceeding $E_{k}$ shown above the 1:1 line and samples taken at irradiance levels below $E_{k}$ shown below the 1:1 line. Over $80 \%$ of the plankton communities were sampled at PAR levels less than the light-saturation index, indicating an overall light limitation. Samples taken within patches were not conspicuous among the set

\section{Primary production inside and outside patches}

Volume-specific productivity rates, normalized to chl $a$, were calculated to determine the effect of primary production on patch formation, persistence, and decline. The subset of experiments where $P$ vs. $E$ curves were available from both inside and outside patches at the same station were used for this comparison $(n=28)$. Primary production inside patches was significantly higher than outside of patches (Fig. 6, p < 0.001). This result was independent of whether 'in situ' or 'hourly averaged' irradiances were used to calculate productivity (see 'Materials and methods'). Average in-patch production rate was nearly 6 -fold higher than outside patches, 1.93 versus $0.33 \mathrm{mg} \mathrm{C}(\mathrm{mg} \mathrm{chl} \mathrm{a})^{-1} \mathrm{~h}^{-1}$. The latter values are based on instantaneous, in situ PAR, measured at time of sample capture. Using the hourly averaged, surface PAR adjusted to sampling depth using the profilespecific attenuation coefficient yielded inside patch production rates of 2.97 and outside rates of 1.52 mg C (mg chl a $)^{-1} \mathrm{~h}^{-1}$, a 2 -fold difference. The difference in estimates based on hourly averaged versus in situ light levels stems both from the higher variability associated with the instantaneous PAR measurement and the significant shading imposed by the denser phytoplankton biomass within the patch. The average in-patch sampling depth was $2.3 \pm 1.2 \mathrm{~m}$ and deeper for outside samples at a depth of $6.7 \pm 3.2 \mathrm{~m}$. Higher production rates were promoted by the often shallower, including surface, depths at which patches formed and which thus received higher irradiance

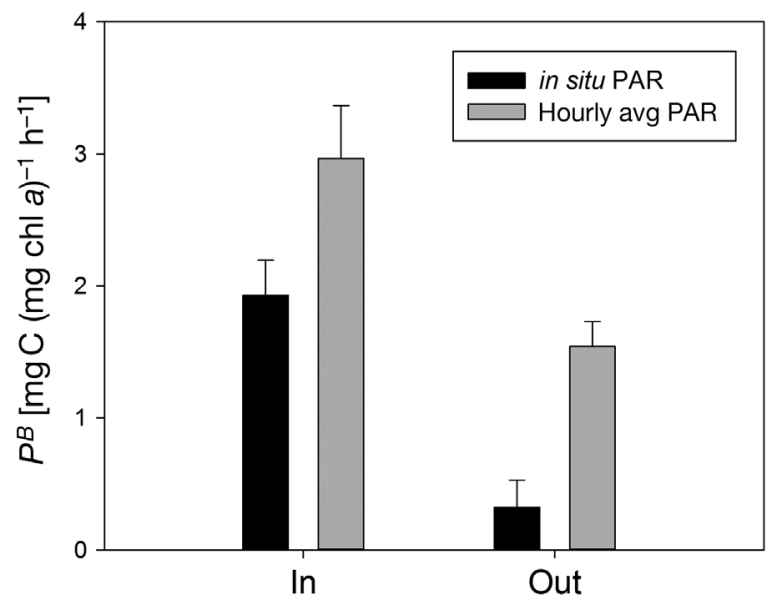

Fig. 6. Average $(+\mathrm{SE})$ volume-specific, instantaneous production rates $\left[\mathrm{mg} \mathrm{C}(\mathrm{mg} \mathrm{chl} a)^{-1} \mathrm{~h}^{-1}\right.$ ] for samples collected inside (In) and outside (Out) patches. Production was higher inside patches $(p<0.001)$ irrespective of whether light levels were based on in situ irradiance or averaged, depthadjusted irradiance from surface measurements. PAR: photosynthetically active radiation 
levels. However, higher production rates were also observed inside patches in instances where the 'outside' sample was taken above the patch sample, suggesting that patch phytoplankton had inherently higher primary production rates, even when patches were located deeper in the water column.

Primary production inside and outside patches was compared to examine the relative contribution of patch production to overall water column production. Within-patch production significantly contributed to

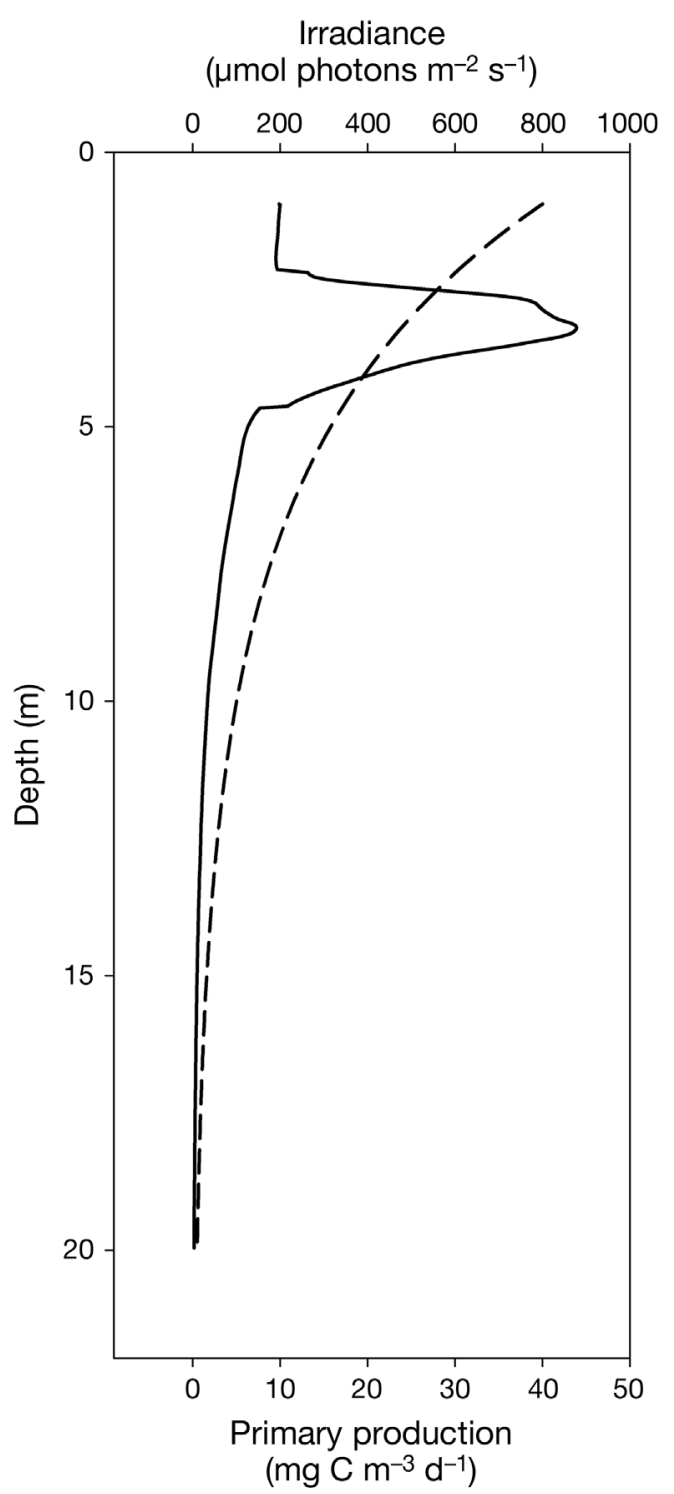

Fig. 7. Profiles of water column production $\left(\mathrm{mg} \mathrm{C} \mathrm{m} \mathrm{C}^{-3}\right.$; solid line) and irradiance ( $\mu \mathrm{mol}$ photons $\mathrm{m}^{-2} \mathrm{~s}^{-1}$; dashed line) representative of conditions in July 2007. Integrated primary production rates within the phytoplankton patch (average vertical extent, $2.4 \mathrm{~m}$ ) contributed $>50 \%$ of total water column production, despite only occupying $12 \%$ of the $20 \mathrm{~m}$ euphotic zone total water column productivity. Estimated total water column production based on averaged chl a profiles and daily irradiances in July 2007 was $1117 \mathrm{mg} \mathrm{C} \mathrm{m}^{-2}$ $\mathrm{d}^{-1}$ (Fig. 7). Primary production within the on average $2.4 \mathrm{~m}$ vertical extent of the patch (ranging from 2.2 to $4.6 \mathrm{~m}$ ) was 607 versus $510 \mathrm{mg} \mathrm{C} \mathrm{m}^{-2} \mathrm{~d}^{-1}$ in the rest of the $20 \mathrm{~m}$ water column. The contribution of withinpatch production to water column total was highest when irradiance was lowest at the beginning and end of the $16 \mathrm{~h}$ light period. However, irradiance-induced changes were minimal, and within-patch production consistently contributed at least $52 \%$ of the total water column production (52-56\%).

\section{DISCUSSION}

Deciphering the mechanistic causes of plankton patchiness is a key factor in predicting the implications of heterogeneous organism distributions for estimates of plankton production, trophic transfer, and elemental cycling rates. Fundamentally, the relative magnitudes of probable biotic causes, including behavior-based aggregations (Genin et al. 2005), grazing (Menden-Deuer \& Fredrickson 2010), and growth (present study), need to be distinguished from physical processes, including shear and buoyancy effects (Birch et al. 2009) and horizontal stirring (McKiver et al. 2009). Knowing the relative magnitudes of each of these processes and the conditions under which they occur allows prediction of patch formation, persistence, and decline. In turn, these predictions allow assessment of the importance of plankton patchiness and their large-scale biogeochemical ramifications for elemental cycling rates, rates of export production, and the ecology and evolution of planktonic species. Thus far, biological rate measurements have been rare in the analysis of plankton patchiness.

Phytoplankton communities sampled from inside patches had a significantly higher photosynthetic potential, over $30 \%$ higher for each $P$ vs. $E$ coefficient than phytoplankton not associated with distinct, heterogeneous structures. Although not statistically significant, the light intensity necessary to saturate photosynthesis was also $>20 \%$ lower for patchassociated communities. This offset is particularly remarkable, since patch-associated communities represented diverse taxonomic phytoplankton groups. Thus, the observed difference cannot be attributed to species-specific physiological differences. Structuredependent differences in photosynthetic potential imply that patch-associated phytoplankton commu- 
nities can enhance rates of layer formation by increased growth, if such growth is not removed by excess grazing. Moreover, layer persistence and maintenance would be supported by the higher photosynthetic potential, as biomass accumulation would counter diffusive losses.

The elevated photosynthetic potential was manifested in higher primary production rates associated with plankton patches, which ultimately led to a disproportionate contribution by plankton patches to total, integrated water column productivity. For example, patches only occupied an average of $\sim 12 \%$ of the vertical extent, but contributed $>50 \%$ to total integrated water column productivity. This concentration and continuous generation of resources for herbivores very likely explains the apparent co-occurrence of predators such as zooplankton and higher trophic levels with plankton patches (Menden-Deuer 2008, Benoit-Bird et al. 2009). Therefore, patches are not only consumption (Menden-Deuer \& Fredrickson 2010) but also production hot spots.

Although production within patches was significantly higher than in the rest of the water column, the observed rates are insufficient to explain patch formation through growth alone in a dynamic water column. Additional processes are required to vertically restrict water masses and maintain these as discrete patches. Birch et al. (2009) pointed out that differential shear can produce horizontal patches as a trace of localized nutrient injections. Therefore, vertical differences in shear are likely important to the separation of water masses and may render some patches tracers of advection (Abraham 1998, Abraham et al. 2000). The model results of Birch et al. (2009) imply that patch water masses are coherent for extended periods of time (several days and longer), a prediction that has been confirmed by empirical observations (Rines et al. 2002, Menden-Deuer 2008). The physical modeling results of Birch et al. (2009) also suggest that patch formation processes can be initiated long before phytoplankton abundances within patches constitute a local maximum, thus 'phytoplankton patches' can exist well before heterogeneity in phytoplankton concentration is detectable. Recent empirical results also support these predictions. MendenDeuer \& Frederickson (2010) found that nutrient concentrations inside phytoplankton patches were significantly lower than outside of patches, suggesting that patch structures were coherent for long enough to reflect differential nutrient uptake by the higher within-patch phytoplankton biomass.

The data presented here emphasize the interplay between physical and biological processes in driving plankton patchiness. On the one hand, physical forcing is clearly important in the differentiation of water masses as the basis for the formation of patches, and maintenance of patches is supported by a high degree of water column stability (McManus et al. 2005). On the other hand, the rates measured here suggest 2 mechanisms by which biological processes drive patch formation, persistence, and intensity.

First, primary production was enhanced within phytoplankton patches. This would contribute to patch formation and persistence by counteracting diffusive losses that erode patch longevity (Stacey et al. 2007, 2009). It is noteworthy that the effective timescales of phytoplankton growth are on the order of days, whereas the time scales of diffusion are on the order of seconds for very small distances $(\mu \mathrm{m})$. In order to be effective to erode patches, diffusion has to be enhanced through turbulent mixing. The frequency of such events depends on storm conditions, which in general are less frequent in the summer in the study area.

Second, grazer-induced losses measured in parallel to production rates presented here showed that grazing by heterotrophic protists within plankton patches was significantly higher than in non-patchy phytoplankton distributions (Menden-Deuer \& Fredrickson 2010). Grazing can contribute to patch erosion on the order of days, but high phytoplankton growth rates within patches were found to exceed grazer-induced loss rates, despite intense grazing pressure (Menden-Deuer \& Fredrickson 2010). Such grazing would significantly enhance nutrient recycling rates and may maintain nutrient supply to phytoplankton contained within patches (Roman et al. 1988, Miller et al. 1995, Glibert 1997). The balance of primary production and grazer-induced loss rates ultimately dictates biomass accumulation rates and thus intensity and persistence of patches. Simultaneous measurements of the shearing and mixing rates together with biological process studies would enable quantitative linkages and predictive capacity relating the degree of fluid dynamics to plankton population dynamics and patchiness (Levin \& Paine 1974).

$P$ vs. $E$ parameters reported here are well within the range of previously reported estimates from temperate coastal areas (Uitz et al. 2008), including the Celtic Sea (Pemberton et al. 2006) and the Gulf of Alaska (Strom et al. 2010). Interestingly, the $P$ vs. $E$ estimates measured here were similar to estimates for low-light-adapted, nutrient-replete, monospecific laboratory cultures (MacIntyre et al. 2002). Particular phytoplankton communities, including a diatom bloom in spring 2009 and a bloom of the toxic raphi- 
dophyte Heterosigma akashiwo in summer 2007, that were at times nearly monospecific, were not distinguishable based on their $P$ vs. $E$ parameters. The high ratios of $E_{k}$ to in situ PAR measurements suggest that irradiance was limiting primary production in $80 \%$ of samples, irrespective of the overall biomass or season. Light limitation for primary production and high-light-adapted phytoplankton, with nearly identical photosynthetic potential, were also observed in the Gulf of Alaska during summer (Strom et al. 2010).

With few exceptions, patch-associated phytoplankton had $P$ vs. $E$ parameters that exceeded but were on the same order of magnitude as $P$ vs. $E$ parameters from non-patch communities. Thus, although parameters for patch phytoplankton showed a significantly higher photosynthetic potential, these shifts, particularly in $\alpha$, were quantitatively not as large as shifts observed in response to other 'treatment effects,' such as iron fertilization (Hiscock et al. 2008), suggesting a less dramatic differentiation among patch and non-patch phytoplankton physiology and photosynthetic potential.

The present study was limited by the fact that Lagrangian tracers were not available to follow patches over time. Patch-associated phytoplankton communities were not sampled repeatedly, and therefore, temporal dynamics in photosynthetic potential were not assessed. Due to this lack of temporally resolved photosynthetic capacity, it is not possible to quantify how much localized acclimation to higher irradiances contributed to the observed higher photosynthetic potential of patch-associated phytoplankton. With patch persistence durations of several days, phytoplankton within patches could acclimate to recent photic exposure and may not necessarily reflect the initial photosynthetic capacity during patch initiation. Patches can also undergo vertical shifts and thus may reflect acclimation to past light exposure regimes. Lagrangian approaches, as used by Landry et al. (2008), that can sample and follow discrete water masses over several days to weeks are essential in identifying whether growth processes allow for the initiation of patch formation.

Several prior studies have included modifications of the bicarbonate radioisotope procedure to estimate grazing effects on primary production measurements. Marra et al. (2012) recently observed an approximately $20 \%$ increase in primary production in samples where grazing pressure was reduced due to experimental manipulation, although the presumed grazing effect was not statistically significant. In experiments of longer duration and larger volume, neither Geider (1988) nor Gallegos \& Vant (1996) found a measurable effect of grazing on primary production measurements, although the latter study identified interesting patterns of differential cycling of chl a (degradation due to grazing) and ${ }^{14} \mathrm{C}$ (incorporation within heterotrophic protist biomass) as predicted by Jackson (1983). In the experiments presented here, using diluted plankton samples, identical, biomass-corrected primary production rates were measured, irrespective of dilution level. Grazing rate measurements made in parallel liter-volume incubations in order to validate this method showed significant grazing rates (on average, $0.25 \mathrm{~d}^{-1}$ ) on the sampled phytoplankton communities (MendenDeuer \& Fredrickson 2010). Thus, although heterotrophic protists were actively feeding in the sampled water masses, grazing was not measured with the combined $P$ vs. E and dilution radioisotope method. Hence, all available data suggest that combining the radioisotope and dilution methods fails to yield measurable grazing rates. It would be possible to use larger volumes and longer incubation times, but that would eliminate the logistical benefits, while generating large volumes of radioactive waste.

Theoretically, the loss rate of phytoplankton in dilution experiments due to grazer-induced mortality should decrease with decreasing plankton concentration as the encounter rate between predator and prey decreases. The success of this principle has been demonstrated abundantly (Calbet \& Landry 2004), although there are valid criticisms of the method (Agis et al. 2007). The failure of this and prior studies to measure a grazing effect may be methodologically rooted. There were deliberate methodological differences in the experimental set-up of the modified $P$ vs. E dilution experiments used here and the procedures typically used (e.g. Landry et al. 2008), including the incubation duration and volume as well as the use of the more sensitive tracer ${ }^{14} \mathrm{C}$ rather than chl a. These changes were made to facilitate more rapid measurements of grazing rates, but appear to have been counterproductive. Many heterotrophic protists are highly sensitive to handling and exposure to foreign materials; thus, they may not have survived to exert their grazing impact. The small volume $(10 \mathrm{ml})$ and short incubation time $(2.5 \mathrm{~h})$ may also have adversely affected the ability to measure grazing pressure. The simulated in situ, larger volume incubations yielded identical estimates of photosynthetic parameters and rates, suggesting that grazer-induced losses did not affect the overall productivity rates in either method. Given the difficulties in adequately handling samples to preserve protistan grazers in a physiologically healthy 
and statistically representative state, the lack of measurable grazing effect is likely due to incubationinduced grazer mortality, rather than a lack of grazing in situ. In addition, dinoflagellates have been observed to be particularly sensitive to even low radiation exposure (Skovgaard \& Menden-Deuer 2003).

Given the difficulty of separating herbivores from phytoplankton due to their similarity in size, it is difficult to incubate phytoplankton without predators and thus achieve a measure of net primary production rather than community production. The data presented here strongly suggest that both the largevolume and photosynthetron methods yielded primary production rates that only recorded autotrophic metabolic activity, including respiration but not consumption by heterotrophs. Therefore, herbivorous losses need to be integrated in model predictions of ${ }^{14} \mathrm{C}$-derived community production rates, which otherwise would present overestimates. Previously measured grazing pressure in these communities accounted for the consumption of $>70 \%$ of primary production inside patches and $\sim 25 \%$ outside of patches (Menden-Deuer \& Fredrickson 2010). Therefore, community production rates are less heterogeneous than net primary production rates, but the respective fate of this structure-dependent production differs, in that inside-patch production primarily fuels trophic transfer and outside-patch production flows towards export production.

Rapid measurements of production rates are required to resolve the temporal and spatial dynamics of biological processes. The 2 independent productivity methods used here yielded statistically indistinguishable results despite the fact that photosynthetron samples were incubated under artificial light and temperature conditions versus the simulated in situ conditions for the large-volume samples. The photosynthetron had the distinct advantage of yielding an order of magnitude lower error estimates for the light utilization coefficient, $\alpha$. Steemann Nielsen (1975) approximated productivity measurements to be accurate within $\pm 30 \%$, which is somewhat higher than the variation in parameter estimates observed here or in Monte Carlo modeling approaches (Pemberton et al. 2006). The smallvolume photosynthetron also yielded an order of magnitude less radioactive waste, and reduced handling time by 1 to $2 \mathrm{~h}$ sample ${ }^{-1}$ because the larger volume method required filtering and other additional handling steps. Combining the reduced handling requirements, less radioactive waste, and reduced uncertainty of $P$ vs. $E$ estimates makes the photosynthetron approach an attractive method to gain insight into the photosynthetic capacity and primary production at relatively high spatial and temporal resolution, although ultimately, instantaneous in situ measurements are needed to eliminate incubation artifacts and achieve proper resolution in time and space.

In conclusion, patch-associated phytoplankton communities had significantly higher photosynthetic potential and primary production rates than nonpatch communities. In addition to this biological mechanism, there is also empirical evidence that physical forcing isolates and maintains water masses coherent over time, possibly contributing localized nutrient injections. Formation of phylogenetically diverse phytoplankton patches are then supported by high rates of primary production. Lagrangian methods would be required to examine whether this difference in photosynthetic potential is present during the initial patch formation or whether it represents a localized adaptation to higher irradiances at shallower depths. Moreover, enhanced primary production can promote the persistence of phytoplankton patches and delay their decline. Reduction in patch intensity could be initiated by structure-dependent grazing pressure (Menden-Deuer \& Fredrickson 2010) or by nutrient limitation due to higher uptake rates within the patch.

Spatial heterogeneity in production rates has ramifications from an oceanographic and ecological perspective. The ability to identify and track phytoplankton patches will allow oceanographers to address topics of long-standing interest, including trophic dynamics, elemental cycling, and export production (Steele 1974). Because of the isolated nature of phytoplankton patches, they may act as test beds for examining topics that are central to ecology, such as the generation and maintenance of species diversity, succession, and competition (Levin \& Paine 1974).

Acknowledgements. I thank the faculty and staff at the Shannon Point Marine Center, Western Washington University, especially K. Fredrickson for assistance with the experiments and S. Strom and her laboratory for their support. RV 'Zoea' skippers G. McKeen and N. Schwarck are gratefully acknowledged as well as the many graduate and undergraduate students who have helped with this research. C. Oviatt generously shared the design of the photosynthetron. D. Rangel provided advice on the analysis, and E. Harvey generated the figures. I also thank R. Horner for kind advice with taxonomy as well as M. J. Perry and J. Marra for helpful discussions of $P$ vs. E experiments. Comments from 3 anonymous reviewers improved this manuscript. This research was supported through grants from the Office of Naval Research (N000140710136 and N000141010124). 


\section{LITERATURE CITED}

Abraham ER (1998) The generation of plankton patchiness by turbulent stirring. Nature 391:577-580

> Abraham ER, Law CS, Boyd PW, Lavender SJ, Maldonado MT, Bowie AR (2000) Importance of stirring in the development of an iron-fertilized phytoplankton bloom. Nature 407:727-730

- Agis M, Granda A, Dolan JR (2007) A cautionary note: examples of possible microbial community dynamics in dilution grazing experiments. J Exp Mar Biol Ecol 341: 176-183

> Alldredge AL, Cowles TJ, MacIntyre S, Rines JEB and others (2002) Occurrence and mechanisms of formation of a dramatic thin layer of marine snow in a shallow Pacific fjord. Mar Ecol Prog Ser 233:1-12

Behrenfeld MJ, Falkowski PG (1997a) A consumer's guide to phytoplankton primary productivity models. Limnol Oceanogr 42:1479-1491

> Behrenfeld MJ, Falkowski PG (1997b) Photosynthetic rates derived from satellite-based chlorophyll concentration. Limnol Oceanogr 42:1-20

- Benoit-Bird KJ, Cowles TJ, Wingard CE (2009) Edge gradients provide evidence of ecological interactions in planktonic thin layers. Limnol Oceanogr 54:1382-1392

Birch DA, Young WR, Franks PJS (2009) Plankton layer profiles as determined by shearing, sinking, and swimming. Limnol Oceanogr 54:397-399

Bjørnsen PK, Nielsen TG (1991) Decimeter scale heterogeneity in the plankton during a pycnocline bloom of Gyrodinium aureolum. Mar Ecol Prog Ser 73:263-267

Bochdansky AB, Bollens SM, Rollwagen-Bollens GC, Gibson AH (2010) Effect of the heterotrophic dinoflagellate Oxyrrhis marina and the copepod Acartia tonsa on vertical carbon flux in and around thin layers of the phytoflagellate Isochrysis galbana. Mar Ecol Prog Ser 402: 179-196

Calbet A, Landry MR (2004) Phytoplankton growth, microzooplankton grazing, and carbon cycling in marine systems. Limnol Oeanogr 49:51-57

> Crawford DW, Stoecker DK (1996) Carbon content, dark respiration and mortality of the mixotrophic planktonic ciliate Strombidium capitatum. Mar Biol 126:415-422

Durham WM, Stocker R (2012) Thin phytoplankton layers: characteristics, mechanisms, and consequences. Annu Rev Mar Sci 4:177-207

Durham WM, Kessler JO, Stocker R (2009) Disruption of vertical motility by shear triggers formation of thin phytoplankton layers. Science 323:1067-1070

Franks PJS (1992) Sink or swim: accumulation of biomass at fronts. Mar Ecol Prog Ser 82:1-12

Franks PJS (1995) Thin layers of phytoplankton: a model of formation by near-inertial wave shear. Deep-Sea Res I 42:75-91

Frenette JJ, Demers S, Legendre L, Dodson J (1993) Lack of agreement among models for estimating the photosynthetic parameters. Limnol Oceanogr 38:679-687

> Gallager SM, Yamazaki H, Davis CS (2004) Contribution of fine-scale vertical structure and swimming behavior to formation of plankton layers on Georges Bank. Mar Ecol Prog Ser 267:27-43

Gallegos CL, Vant WN (1996) An incubation procedure for estimating carbon-to-chlorophyll ratios and growthirradiance relationships of estuarine phytoplankton. Mar Ecol Prog Ser 138:275-291
Geider RJ (1988) Estimating the growth and loss rates of phytoplankton from time-series observations of ${ }^{14}$-Cbicarbonate uptake. Mar Ecol Prog Ser 43:125-138

> Geider RJ, MacIntyre HL, Kana TM (1997) Dynamic model of phytoplankton growth and acclimation: responses of the balanced growth rate and the chlorophyll a:carbon ratio to light, nutrient-limitation and temperature. Mar Ecol Prog Ser 148:187-200

Genin A, Jaffe JS, Reef R, Richter C, Franks PJS (2005) Swimming against the flow: a mechanism of zooplankton aggregation. Science 308:860-862

- Glibert PM (1997) Interactions of top-down and bottom-up control in planktonic nitrogen cycling. Hydrobiologia 363:1-12

> Graff J, Rynearson T (2011) Extraction method influences the recovery of phytoplankton pigments from natural assemblages. Limnol Oceanogr Methods 9:129-139

> Hiscock MR, Lance VP, Apprill AM, Bidigare RR and others (2008) Photosynthetic maximum quantum yield increases are an essential component of the Southern Ocean phytoplankton response to iron. Proc Natl Acad Sci USA 105:4775-4780

> Jackson GA (1983) Zooplankton grazing effects on ${ }^{14} \mathrm{C}$ based phytoplankton production measurements: a theoretical study. J Plankton Res 5:83-94

Jassby AD, Platt T (1976) Mathematical formulation of the relationship between photosynthesis and light for phytoplankton. Limnol Oceanogr 21:540-547

Kolber Z, Falkowski PG (1993) Use of active fluorescence to estimate phytoplankton photosynthesis in situ. Limnol Oceanogr 38:1646-1665

> Landry MR, Hassett RP (1982) Estimating the grazing impact of marine micro-zooplankton. Mar Biol 67:283-288

Landry MR, Decima M, Simmons MP, Hannides CCS, Daniels E (2008) Mesozooplankton biomass and grazing responses to Cyclone Opal, a subtropical mesoscale eddy. Deep-Sea Res II 55:1378-1388

> Levin SA, Paine RT (1974) Disturbance, patch formation, and community structure. Proc Natl Acad Sci USA 71: 2744-2747

MacIntyre HL, Kana TM, Anning T, Geider RJ (2002) Photoacclimation of photosynthesis irradiance response curves and photosynthetic pigments in microalgae and cyanobacteria. J Phycol 38:17-38

> Marra J (2009) Net and gross productivity: weighing in with ${ }^{14} \mathrm{C}$. Aquat Microb Ecol 56:123-131

Marra J, Capuzzo E, Montecino V (2012) Potential grazing effects in incubations with ${ }^{14} \mathrm{C}$. Aquat Biol 14:283-288

McKiver W, Neufeld Z, Scheuring I (2009) Plankton bloom controlled by horizontal stirring. Nonlinear Process Geophys 16:623-630

McManus MA, Cheriton OM, Drake PJ, Holliday DV, Storlazzi CD, Donaghay PL, Greenlaw CF (2005) Effects of physical processes on structure and transport of thin zooplankton layers in the coastal ocean. Mar Ecol Prog Ser 301:199-215

> Menden-Deuer S (2008) Spatial and temporal characteristics of plankton-rich layers in a shallow, temperate fjord. Mar Ecol Prog Ser 355:21-30

> Menden-Deuer S, Fredrickson K (2010) Structure-dependent, protistan grazing and its implication for the formation, maintenance and decline of plankton patches. Mar Ecol Prog Ser 420:57-71

Menden-Deuer S, Lessard EJ (2000) Carbon to volume relationships for dinoflagellates, diatoms, and other protist 
plankton. Limnol Oceanogr 45:569-579

Miller CA, Penry DL, Glibert PM (1995) The impact of trophic interactions on rates of nitrogen regeneration and grazing in Chesapeake Bay. Limnol Oceanogr 40: 1005-1011

Montagnes DJS, Berges JA (2004) Determining parameters of the numerical response. Microb Ecol 48:139-144

Montagnes DJS, Lessard EJ (1999) Population dynamics of the marine planktonic ciliate Strombidinopsis multiauris: its potential to control phytoplankton blooms. Aquat Microb Ecol 20:167-181

Oviatt CA, Hyde KJW, Keller AA, Turner JT (2007) Production patterns in Massachusetts Bay with outfall relocation. Estuaries Coasts 30:35-46

Parsons TR, Maita Y, Lalli CM (1984) A manual of chemical and biological methods for seawater analysis. Pergamon Press, New York, NY

Pemberton KL, Clarke KR, Joint I (2006) Quantifying uncertainties associated with the measurement of primary production. Mar Ecol Prog Ser 322:51-59

Platt T, Gallegos CL, Harrison WG (1980) Photoinhibition of photosynthesis in natural assemblages of marine phytoplankton. J Mar Res 38:687-701

Putt M, Stoecker DK (1989) An experimentally determined carbon: volume ratio for marine 'oligotrichous' ciliates from estuarine and coastal waters. Limnol Oceanogr 34: 1097-1103

Rines JEB, Donaghay PL, Dekshenieks MM, Sullivan JM, Twardowski MS (2002) Thin layers and camouflage: hidden Pseudo-nitzschia spp. (Bacillariophyceae) populations in a fjord in the San Juan Islands, Washington, USA. Mar Ecol Prog Ser 225:123-137

Robinson C, Tilstone GH, Rees AP, Smyth TJ and others (2009) Comparison of in vitro and in situ plankton production determinations. Aquat Microb Ecol 54:13-34

Roman MR, Ducklow HW, Fuhrman JA, Garside C, Glibert PM, Malone TC, McManus GB (1988) Production, consumption and nutrient cycling in a laboratory mesocosm. Mar Ecol Prog Ser 42:39-52

Editorial responsibility: Graham Savidge,

Portaferry, UK
Siegel DA, Doney SC, Yoder JA (2002) The North Atlantic spring phytoplankton bloom and Sverdrup's critical depth hypothesis. Science 296:730-733

Skovgaard A, Menden-Deuer S (2003) Long-term exposure of dinoflagellates to ${ }^{14}$ carbon: effects on growth rate and measurements of carbon content. J Plankton Res 25: 1005-1009

Stacey MT, McManus MA, Steinbuck JV (2007) Convergences and divergences and thin layer formation and maintenance. Limnol Oceanogr 52:1523-1532

Stacey M, McManus M, Steinbuck J (2009) Response to 'Plankton layer profiles as determined by shearing, sinking, and swimming' by D. A. Birch, W. R. Young, and P. J. S. Franks. Limnol Oceanogr 54:400

Steele JH (1974) Spatial heterogeneity and population stability. Nature 248:83

Steemann Nielsen E (1952) The use of radio-active carbon $\left({ }^{14} \mathrm{C}\right)$ for measuring organic production in the sea. J Cons Int Explor Mer 18:117-140

Steemann Nielsen E (1975) Marine photosynthesis: with special emphasis on the ecological aspects. Elsevier Scientific, Amsterdam

Strickland J, Parsons T (1972) A practical handbook of seawater analysis, 2nd edn. Fisheries Research Board of Canada, Ottawa

Strom SL, Macri EL, Fredrickson KA (2010) Light limitation of summer primary production in the coastal Gulf of Alaska: physiological and environmental causes. Mar Ecol Prog Ser 402:45-57

> Uitz J, Huot Y, Bruyant F, Babin M, Claustre H (2008) Relating phytoplankton photophysiological properties to community structure on large scales. Limnol Oceanogr 53: 614-630

Webb WL, Newton M, Starr D (1974) Carbon dioxide exchange of Alnus rubra. Oecologia 17:281-291

Welschmeyer N, Lorenzen C (1984) Carbon-14 labeling of phytoplankton carbon and chlorophyll a carbon: determination of specific growth rates. Limnol Oceanogr 29: 135-145

Submitted: February 21, 2012; Accepted: July 27, 2012 Proofs received from author(s): November 3, 2012 